\title{
Communications
}

\section{Enantioselective Addition of Diethylzinc to Aldehydes in the Presence of Amino Thiocyanates Derived from L-Prolinol}

\author{
Myung-Jong Jin* and Young-Mok Kim \\ School of Chemical Science \& Engineering, Inha University, Incheon 402-751, Korea. *E-mail: mjjin@inha.ac.kr \\ Received October 5, 2004
}

Key Words : Enantioselective addition, Amino thiocyanate, Diethylzinc, Aldehyde

Asymmetric metal catalysis is now recognized as the most promising area in the synthesis of optically active organic compounds. One attractive method that leads to the formation of optically active secondary alcohols is catalytic enantioselective addition of organozinc reagent to aldehyde. ${ }^{1}$ Numerous elegant and efficient catalysts have been developed for this reaction, in which most of them are based on protic chiral ligands such as amino alcohols, ${ }^{2}$ diols, ${ }^{3}$ diamines, ${ }^{4}$ and their derivatives. ${ }^{5}$ Although amino thioacetates 2 have been used with success for the diethylzinc-aldehyde addition, aprotic ligands have not received much attention in this area. ${ }^{6}$ Thus, it should be of interest to explore the catalytic ability of aprotic ligands. We present new chiral $N, S$-chelate aprotic ligands $\mathbf{3}$, together with their catalytic applicability in the diethylzinc-aldehyde addition.

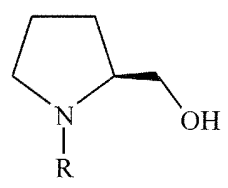

1a: $\mathrm{R}=\mathrm{Bn}$ $1 \mathrm{~b}: \mathrm{R}=\mathrm{Bu}$

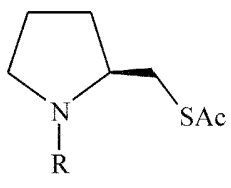

2

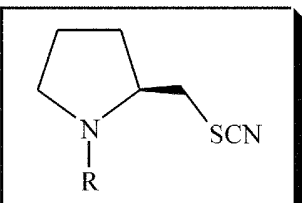

3a: $\mathrm{R}=\mathrm{Bn}$ 3b: $R=B u$
Similarly to the previous method, ${ }^{6}$ amino thiocyanate $\mathbf{3} \mathbf{a}^{7}$ was readily prepared in $80 \%$ yields by treatment of (-)-1benzyl-2-pyrrolidinemethanol 1a with methanesulfonyl chloride (1.0 equiv) and triethylamine (1.0 equiv) in methylene chloride at $-20{ }^{\circ} \mathrm{C}$, followed by subsequent displacement with sodium thiocyanate (2.4 equiv) in $\mathrm{H}_{2} \mathrm{O}$ at $35^{\circ} \mathrm{C}$. Synthesis of amino thiocyanate $\mathbf{3 b}$ was also achieved in $73 \%$ yield from (-)-1-butyl-2-pyrrolidinemethanol $\mathbf{1 b}$. The chiral aprotic ligands were then applied to the enantioselective diethylzinc-aldehyde addition. For optimization of the reaction conditions, the reaction of $\mathrm{Et}_{2} \mathrm{Zn}$ with benzaldehyde using ligand 3a was carried out. Increasing the amount of 3a from 4 to $8 \%$ led to a small increase in the enantioselectivity and $6 \mathrm{~mol} \%$ of $\mathbf{3 a}$ was enough to give satisfactory enantioselectivity and reactivity (entries 3-5).
When the reaction was carried out at $0{ }^{\circ} \mathrm{C}$, the enantioselectivity was almost same with decreased reactivity Table 1. Enantioselective Addition of Diethylzinc to Aldehydesa (entry 7). Gratifyingly enough, the addition took place in high ee of up to $92 \%$ with high yield. Other aromatic aldehydes were also converted to the corresponding $(R)$ secondary alcohols with high optical purity in high yields (entries 9-13). For an aliphatic heptanal, moderate enantioselectivity was obtained (entry 14). Toluene gave lower ee than hexane, but with high conversions (entries 6 and 10). Changing ligand 3a to $3 \mathbf{b}$ caused only a slight drop in enantioselectivity (entries 8 and 11). The results are sum-

Table 1. Enantioselective Addition of Diethylzinc to Aldehydes ${ }^{a}$

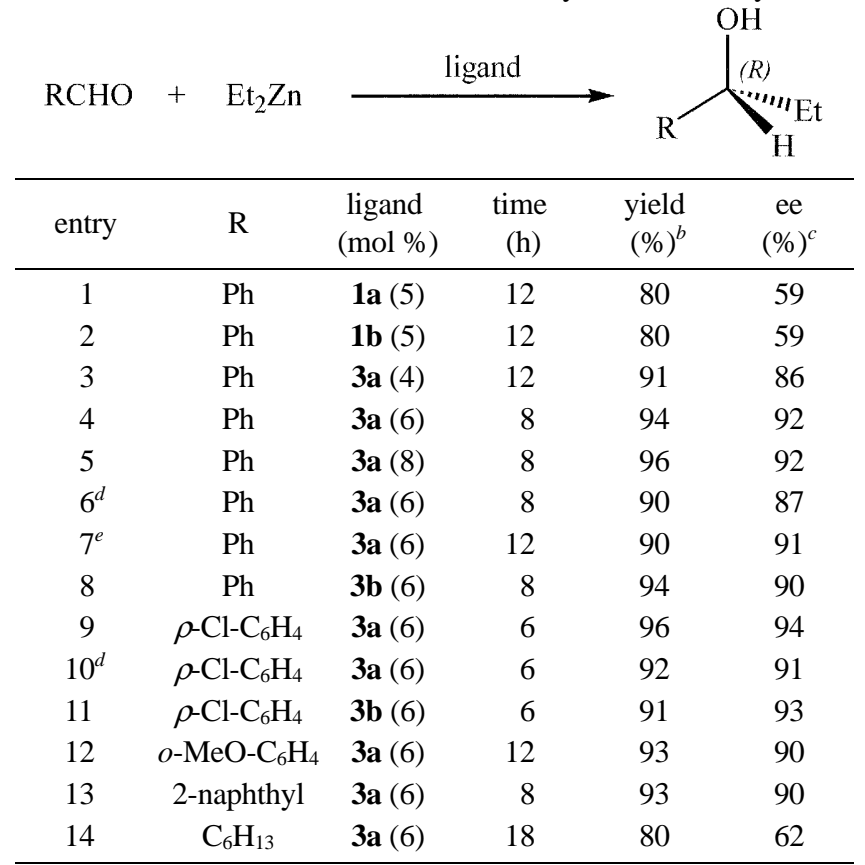

${ }^{a}$ Reactions were carried out in hexane at RT using 2 equiv. of $\mathrm{Et}_{2} \mathrm{Zn}$ unless otherwise noted. Absolute configuration was assigned by the sign of the optical rotation and elution order from a chiral OD column. ${ }^{b}$ Isolated yield. ${ }^{c}$ Entries 1-13: determined by HPLC analysis (chiralcel OD column). Entry 14: determined by GC analysis ( $\beta$-DEX chiral column). ${ }^{d}$ Toluene was used as solvent. ${ }^{e}$ The reaction temperature was 0 ${ }^{\circ} \mathrm{C}$. 
marized in Table 1. It is noteworthy that amino thiocyanates $\mathbf{3}$ give higher reaction rate and better asymmetric induction than amino alcohol 1. This catalytic system involving aprotic ligands $\mathbf{3}$ would not match with the general mechanistic model ${ }^{1}$ of the diethylzinc-aldehyde addition because the aprotic ligands do not possess an acidic hydrogen atom. An unusual mechanism may be operative in the addition. We assume that simple coordination of nitrogen and sulfur atoms to the zinc of diethylzinc generate an efficient chiral catalyst.

A typical procedure for the present catalytic reaction is described as follows: Benzaldehyde $(106 \mathrm{mg}, 1.0 \mathrm{mmol})$ was added to a solution of ligand $\mathbf{3 a}(12 \mathrm{mg}, 0.05 \mathrm{mmol})$ in hexane $(1.7 \mathrm{~mL})$ at $0{ }^{\circ} \mathrm{C}$. Diethylzinc $(2 \mathrm{~mL}, 1.0 \mathrm{M}$ in hexane) was then added dropwise. The mixture was stirred at room temperature, observing the progress of the reaction by TLC. The reaction was quenched by the addition of dilute aqueous $\mathrm{NH}_{4} \mathrm{Cl}$. The combined extracts were dried over anhydrous $\mathrm{MgSO}_{4}$ and evaporated under reduced pressure. The residue was purified by column chromatography.

In conclusion, we have demonstrated that new chiral aprotic amino thiocyanates catalyze efficiently the enantioselective addition of dialkylzinc to aldehydes. Our study may open the way to the use of aprotic ligands in the dialkylzinc-aldehyde addition. Further synthesis of chiral aprotic ligands are underway in our laboratory.

Acknowledgement. We thank the Advanced Biosepa- ration Technology Center of Inha University for financial support.

\section{References}

1. For reviews: (a) Noyori, R.; Kitamura, M. Angew. Chem. Int. Ed. Engl. 1991, 30, 49. (b) Soai, K.; Niwa, S. Chem. Rev. 1992, 92, 833.

2. (a) Paleo, M. R.; Cabeza, I.; Sardina, J. J. Org. Chem. 2000, 65, 2108. (b) Dangel, B. D.; Polt, R. Org. Lett. 2000, 2, 3003. (c) Superchi, S.; Mecca, T.; Giorgio, E.; Rosini, C. Tetrahedron: Asymmetry 2001, 12, 1235. (d) Priego, J.; Mancheno, O. G.; Cabrera, S.; Carretero, J. C. J. Org. Chem. 2002, 67, 1346. (e) Park, D. H.; Choi, H. J.; Lee, S.-g. Bull. Korean Chem. Soc. 2003, 24, 1346. (f) Fontes, M.; Verdaguer, X.; Sola, L.; Pericas, M.; Riera, A. J. Org. Chem. 2004, 69, 2532.

3. (a) Rosini, C.; Franzini, L.; Pini, D.; Salvadori, P. Tetrahedron: Asymmetry 1990, 1, 587. (b) Weber, B.; Seebach, D. Tetrahedron 1994, 50, 7473. (c) Heckel, A.; Seebach, D. Angew. Chem. Int. Ed. Engl. 2000, 39, 163.

4. (a) Niwa, S.; Soai, K. J. Chem. Soc., Perkin Trans. 1 1991, 28, 2717. (b) Conti, S.; Falorni, M.; Giacomelli, G.; Soccolini, F. Tetrahedron 1992, 48, 8993.

5. (a) Katsuji, I.; Kimula, Y.; Okamura, H.; Katsuki, T. Synlett 1992, 573. (b) Qiu, J.; Guo, C.; Zhang, X. J. Org. Chem. 1997, 62, 2665. (c) Yus, M.; Ramon, D. J.; Prieto, O. Tetrahedron: Asymmetry 2003, 14, 1103.

6. (a) Jin, M.-J.; Kim, S.-H.; Jung, J.-A.; Lee, H.-Y. Bull. Korean Chem. Soc. 2000, 21, 33 .

7. Selected data for $3 \mathrm{a}:{ }^{1} \mathrm{H} \mathrm{NMR}\left(\mathrm{CDCl}_{3}, 250 \mathrm{MHz}\right) \delta 7.33-7.15(\mathrm{~m}$, $5 \mathrm{H}), 3.50(\mathrm{~d}, J=13.3 \mathrm{~Hz}, 1 \mathrm{H}), 3.42(\mathrm{~d}, J=13.3 \mathrm{~Hz}, 1 \mathrm{H}), 3.41(\mathrm{~m}$, $1 \mathrm{H}), 2.85(\mathrm{~m}, 1 \mathrm{H}), 2.49(\mathrm{~m}, 2 \mathrm{H}), 2.37(\mathrm{~m}, 1 \mathrm{H}), 2.13-1.85(\mathrm{~m}, 2 \mathrm{H})$, $1.85-1.56(\mathrm{~m}, 2 \mathrm{H}) ;[\alpha]_{\mathrm{D}}^{20}-13.9\left(\mathrm{c} 0.7, \mathrm{CHCl}_{3}\right) ; \mathrm{MS}(\mathrm{EI}) \mathrm{m} / \mathrm{z} .232$ $(\mathrm{M}+)$. 